Linha D'Água (Online), São Paulo, v. 29, n. 1, p. 67-83, jun. 2016

\title{
DOIS ASPECTOS DE LINGUAGEM E UM POEMA: UM ESTUDO ESTILÍSTICO DE "ÁGUA-FORTE"
}

\author{
TWO ASPECTS OF LANGUAGE AND A POEM: ONE \\ STYLISTICS ANALYSIS OF "ÁGUA FORTE"
}

\author{
Isabel Cristina Ferreira Teixeira* \\ Universidade Federal do Pampa, Bagé, RS, Brasil
}

\begin{abstract}
Resumo: Este estudo organiza-se em torno de uma experiência desenvolvida em sala de aula, mais especificamente em Estudos Linguísticos, disciplina cursada por estudantes dos primeiros semestres do curso de Licenciatura em Letras. Nela comeccamos a reflexão sobre a constituição disciplinar da linguística pelas ideias estruturalistas. Jakobson logo aparece com seus artigos fundadores sobre os eixos da organizaç̦a da linguagem associados à afasia e sobre as funçōes da linguagem, caracterizando a função poética como aquela que "projeta o princípio da equivalência do eixo da seleção sobre eixo da combinacçōo" (1985, p. 130). Mas como compreender esses conceitos que descrevem a expressividade dos elementos linguísticos? A ideia é aplicá-los à linguagem em seus diferentes usos. 0 poema é uma dessas possibilidades. Apresentamos então o estudo feito para os estudantes e com os estudantes que analisa o funcionamento das duas figuras polares de estilo - a metáfora e a metonímia - aplicadas ao poema "Água-forte" de Manuel Bandeira (1986). Baseados nos prinćpios estruturalistas de Saussure (1974) e Jakobson (1985), aproximamos os eixos de organização da linguagem a essas figuras. Essa análise favorece a descoberta do sentido, produz possibilidades de leitura e, principalmente, permite a observacã̃o de efeitos discursivos relacionados ao conhecimento da expressividade dos elementos linguísticos.
\end{abstract}

Palavras-chave: Estilistica; Linguística; Discuiso; Paradigma; Sintagma.

Abstract: This study is based on a class experience, in Estudos Linguisticos, course taken by students of the degree in Languages. We started by reflecting about structural linguistics. Soon Jakobson shows up with his essential articles about the two complementary axes of language related to aphasic disturbances and about the functions of language, emphasizing the role of the poetic function as the one which "projects the principle of equivalence from the axis of selection into the axis of combination" (2016, p. 7). To understand these concepts which point out to the expressivity in language, we apply them in different texts, in different uses of language. The poem is one of them. Then we present the study done for the students and with them which analyses the two polar figures of speech - metaphor and metonymy - applied to the Manuel Bandeiras' poem "Água-forte" (1986). Based on the structural principles elaborated by Saussure (1974) and Jakobson (1985), we bring the two axes of organization of language close to these figures. This analysis allows observing the constitution of meaning, produces multiple readings and, mainly, allows to observe discoursive effects related to the knowledge of expressive qualities in language.

Keywords: Stylistics; Linguistics; Discourse; Paradigm; Syntagm.

* Professora da Universidade Federal do Pampa - UNIPAMPA, Bagé, RS, Brasil; isabelcristinaft@gmail.com 
Linha D'Água (Online), São Paulo, v. 29, n. 1, p. 67-83, jun. 2016

\section{Introdução}

Este artigo desenvolve-se em torno de uma experiência desenvolvida em sala de aula, em Estudos Linguísticos, disciplina cursada por estudantes dos primeiros semestres do curso de Licenciatura em Letras. Nela começamos uma reflexão sobre a constituição disciplinar da linguística pelas ideias de Saussure (1974) e de Jakobson (1985), dentre outros autores e acontecimentos considerados relevantes ao tema. Na tentativa de relacionar teoria e prática passamos a realizar análises, segundo procedimentos estruturalistas, ora de peças publicitárias, ora de charges, ora de textos exclusivamente verbais, dentre outros. $\mathrm{O}$ curso de licenciatura, talvez mais do que outros, deve pensar no modo como os saberes científicos, as teorias acadêmicas contribuem para a compreensão de um objeto de estudo que eventualmente se transforma em objeto de ensino. Chegamos ao poema, desta forma, procurando lugares onde poderíamos observar em funcionamento algumas das noções formuladas pelos estruturalistas estudados. E, inspirados na discussão feita por Cara (1986) sobre a distinção entre lirismo e gêneros literários, chegamos a "Água-Forte", poema citado pela autora, não muito depois de avaliar que:

O ritmo de recepção da poesia lírica é também um ritmo associativo, baseado nas relações de contiguidade da linguagem, capazes de propor uma leitura de aproximações entre elementos do texto que não estão necessariamente numa sequência lógica: uma imagem aqui, uma imagem ali, um ritmo cá, uma sonoridade lá, e eis o mergulho de uma existência apenas poética (ibid., p. 60).

De considerações como as mencionadas acima, de que o poema lírico organiza-se na contiguidade, mas remete a associações fora desse eixo e fora de uma sequência considerada lógica, aproximamo-nos de Jakobson (1985) cuja teoria deu consistência a uma possibilidade de leitura do poema que nos pareceu plausível, surpreendente e encantadora.

Vale destacar também que Cara (1986) distingue lírico enquanto substantivo e enquanto adjetivo. No primeiro caso, o substantivo refere-se a uma classificação geral e clássica dos gêneros como lírico, épico e dramático. Segundo essa distinção, podemos agrupar como líricas obras que contenham um conjunto de características gerais, tradicionalmente atribuídas ao gênero. São considerados líricos, portanto, "poemas não muito longos, sem personagens claramente delineados, onde o

1 Inspiraram-me também para esse estudo as aulas da professora Lígia Millitz da Costa, com quem, na já distante década de 80, ainda estudante do curso de Letras, da Universidade Federal de Santa Maria, conheci possibilidade semelhante de análise para o poema. 
Linha D'Água (Online), São Paulo, v. 29, n. 1, p. 67-83, jun. 2016

ritmo e a melodia servem para expressar o estado da alma de um 'eu'(...)" (ibid., p. 56). No segundo, quando lírico é adjetivo, significam, nas palavras de Cara, "uma qualidade ${ }^{2}$ que decorre de traços estilísticos ${ }^{3}$ específicos que podem - ou não - estar presentes num texto, independente do gênero a que pertence" (ibid., p. 56). A ideia de que traços estilísticos podem estar presentes em qualquer texto, independentemente do gênero a que pertencem também nos encaminha a Jakobson (1985) que, ao descrever as funções da linguagem, não liga nenhuma delas exclusivamente ao texto literário. Sobre a função poética, vale dizer que predomina nas mensagens em que haja um trabalho sobre a camada material do signo e que esse trabalho seja mais evidente que outras funções.

Estudar princípios e procedimentos estruturalistas não significa apenas recuperar aspectos históricos da linguística, mas observar o modo como essa perspectiva continua presente nas ciências da linguagem, no ensino de língua portuguesa e nas publicações voltadas a esse fim; e também avaliar o modo como as teorias que the seguem, produzem noções em torno das lacunas deixadas pelo estruturalismo.

No que se refere a publicações, mais especificamente, aos livros didáticos, observamos que, ao lado do enfoque gramatical, costumam ser apresentados princípios estruturalistas, tais como, os de língua e fala, os de significante e significado, o conceito de língua como sistema; e, notadamente a partir da década de 70, fundamentos funcionalistas, tais como, fatores comunicacionais e funções da linguagem. Mais recentemente os livros didáticos têm abarcado fundamentos oriundos de teorias enunciativas, pragmáticas e discursivas. Esses aportes teóricos tentam inserir no processo de representação elementos que haviam sido deixados de fora pelo estruturalismo. As teorias linguísticas contemporâneas procuram (re)colocar o sujeito, a história e o referente, que passam a ser considerados fundamentais para a constituição do sentido (GUIMARÃES, 1995). Essas modificações não tiram o mérito dos conceitos elaborados pelo estruturalismo que são constantemente recuperados, seja para serem adotados, seja para serem refutados, o que confirma a importância dessa escola. Não está descartada, portanto, a necessidade de conhecer e de avaliar a contribuição precursora do estruturalismo e de seus principais representantes. Esse é o objetivo deste estudo que, em linhas gerais, apresenta princípios elaborados por Saussure (1974) e por Jakobson (1985); e, especificamente, aplica os eixos de organização da linguagem, apresentados por Saussure e retomados por Jakobson que os desenvolve e os relaciona ao que

\footnotetext{
2 Grifo da autora

3 Grifo da autora
}

TEIXEIRA, I. C. F. Dois aspectos de linguagem e um poema: um estudo estilístico de "Água-Forte" 
Linha D'Água (Online), São Paulo, v. 29, n. 1, p. 67-83, jun. 2016

chama de figuras polares de estilo: a metáfora e a metonímia, na interpretação do poema Água-forte de Manuel Bandeira.

\section{Estrutura e estilo}

Indiciando sua importância e impacto no cenário brasileiro, observamos o termo estruturalismo em compêndios especializados de linguística, em gramáticas, em livros didáticos de língua portuguesa, voltados para diferentes graus de ensino, em dicionários especializados das ciências da linguagem e mesmo dicionários gerais de língua portuguesa. Exemplo disso é o verbete para o termo que consta no Dicionário Houaiss da Língua Portuguesa. O termo é descrito como

Toda abordagem de análise que define os fatos linguísticos a partir de noções saussurianas de estrutura e de sistema linguística estrutural [Aplica-se à Escola de Praga, à glossemática (escola dinamarquesa) e às teorias descritivistas norte-americanas; após 45, o estruturalismo saiu do domínio da linguística e conquistou posição noutras áreas do saber, como etnologia, antropologia, filosofia, sociologia, economia, e teoria literária] (2001, p. 1267).

Observa-se que não é a qualquer estrutura que o verbete se refere. A descrição remete ao campo da linguística, apontando para elementos teóricos e históricos que evidenciam a estabilidade do sentido do termo e o reconhecimento do estruturalismo linguístico no país.

$\mathrm{O}$ verbete permite várias reflexões, mas destacamos duas, porque envolvem autores fundamentais para este estudo: Saussure e Jakobson. A primeira parte da expressão "noçôes saussurianas de estrutura e sistema", em que a menção ao iniciador da linguística contemporânea aparece sob a forma de adjetivo - saussuriano -, indiciando o reconhecimento não só das noções, que se firmam a partir da publicação do Curso de linguística geral, mas do autor que direta ou indiretamente as popularizou, de modo que o nome próprio - Saussure - pode ser dispensado. A segunda reflexão aponta para a possibilidade de associarmos as vertentes estruturalistas listadas - Escola de Praga, glossemática, descritivistas norte-americanos - a Jakobson que, embora não tenha sido nomeado, é um de seus mais conhecidos representantes e nos interessa, de modo mais específico, para este estudo.

O linguista pode ser relacionado aos formalistas de Praga, ao funcionalismo ou, desvinculado de rótulos, pode ser considerado um linguista plural a quem interessava tudo o que tem a ver com a linguagem (ILARI, 2004). Jakobson interessou-se também por questões de estilo e pelo domínio da estilística. Em uma dessas 
Linha D'Água (Online), São Paulo, v. 29, n. 1, p. 67-83, jun. 2016

ocasiões, explica que a linguística descreveu adequadamente a estrutura do código linguístico, mas que essa descrição se limita a "representações padronizadas". E chama atenção para a ideia de que o código linguístico não se resume a tais representações. Deve ser levada em consideração a ideia de que “(...) a estratificação estilística dos símbolos léxicos, bem como as variações pretensamente 'livres', na sua constituição como nas regras de suas combinações, são 'previstas e preparadas' pelo código" (1985, p. 77). Da citação depreendemos que o léxico tem funcionamentos que não se limitam a regras gramaticais ou fonológicas de combinação, referem-se também à estilística; compreendemos também que tais funcionamentos são próprios do código, que os prevê e prepara. Câmara Jr. argumenta em direção semelhante e, em seus Dispersos de J. Mattoso Câmara Jr., a estilística é definida como "a parte do estudo da linguagem que se opõe à gramática, a qual trata da língua representativa. O papel da estilística é depreender todos os processos linguísticos que permitem a atuação da manifestação psíquica e do apelo dentro da linguagem intelectiva" (2004, p. 176). Tanto para Jakobson como para Câmara Jr., o estilo pertence à língua, ou ao código; a estilística estuda o valor expressivo das formas linguísticas e os efeitos produzidos por esses apelos no leitor ou interlocutor.

É dessas questões que tratamos neste estudo: estrutura e estilo, revisadas enquanto princípios e aplicadas enquanto procedimento de análise. Para isso, realizamos um percurso teórico que desenvolve aspectos da teoria saussuriana e da de Jakobson - enfatizando as noções de paradigma e sintagma, relacionados à metáfora e metonímia; e de função poética - para, a seguir, analisarmos Água-forte.

\subsection{Princípios saussurianos: paradigma, sintagma e valor da língua}

O Curso de linguística geral (CLG), obra póstuma do linguista Ferdinand de Saussure, foi publicado em 1916 e, segundo Ilari (2004), colaborou para a afirmação do estruturalismo na Europa. Não foi escrito por Saussure, trata-se de uma obra oral, feita a partir da coleta e da organização dos textos escritos do mestre, usados para os cursos que ministrou entre os anos de 1907 e 1911, somados às anotações de aula de dois de seus alunos, professores de Genebra, Charles Bally e Albert Séchehaye (DOSSE, 1993). Apesar dessa circunstância particular, que põe em dúvida as ideias apresentadas na obra e aponta para a possibilidade de uma simplificação excessiva, o livro fez muito sucesso e tem sido desde então uma das principais referências para o estruturalismo linguístico (ILARI, 2004). O CLG estabelece o objeto, os princípios e procedimentos da linguística contemporânea. A língua, objeto da linguística, é definida como sendo "ao mesmo tempo, um produto social da faculdade de linguagem e um conjunto de convenções necessárias, 
Linha D'Água (Online), São Paulo, v. 29, n. 1, p. 67-83, jun. 2016

adotadas pelo corpo social para permitir o exercício dessa faculdade nos indivíduos" (SAUSSURE, 1974, p. 17). Trata-se então de um sistema de signos convencionalmente aceitos como tal e adotado pela sociedade. Nesse sistema, "todos os termos são solidários e o valor de um resulta tão somente da presença simultânea de outros... " (ibid., p. 133). Nessa perspectiva, a língua constitui-se não só em um sistema convencional, mas em um sistema de relações cujos elementos não têm valor se considerados independentemente das relações que estabelecem com os outros do sistema, sejam de equivalência, sejam de oposição. Para a análise que desenvolvemos, importa o signo, seu valor e as relações estabelecidas por ele. Portanto, para compreensão de aspectos do funcionamento desse sistema e do modo como ele significa, precisamos da teoria do valor linguístico, considerada por Ilari (2004) como central para a compreensão do fenômeno linguístico; e das relações paradigmáticas e sintagmáticas, princípios teóricos que serão aplicados ao objeto que neste estudo nos propomos analisar.

Comecemos pelo signo, unidade do sistema, que não une a coisa à palavra, mas uma imagem acústica a um conceito. Trata-se de uma entidade de dupla face, formada por significante (imagem acústica) e significado (conceito). Poderíamos supor que a significação surge dessa relação, mas "ela não é (...) mais que a contraparte da imagem auditiva” (SAUSSURE, 1974, p. 133), a produzir, relativamente a uma palavra, uma ideia de domínio fechado existente por si próprio. $\mathrm{O}$ signo é a relação que une significante e significado, tem a propriedade de representar, mas é "de igual modo a contraparte dos outros signos da língua" (ibid., p. 133). E é a partir dessa ideia que compreendemos a teoria do valor. O signo significa em função de outros que the sejam semelhantes, dessemelhantes ou contíguos: o valor do signo é determinado pelos que o rodeiam e que não estão presentes. $O$ valor linguístico de mulher, por exemplo, se estabelece em função de não ser moça, adolescente, anciã, associações baseadas na semelhança, ou homem, associação baseada na diferença. $\mathrm{O}$ signo pode ser pensado positivamente por seu conteúdo in praesentia e negativamente - in absentia - pelas relações que estabelece com os outros elementos do sistema.

O fato de o signo representar em função dos outros elementos do sistema nos remete à noção de sintagma e de paradigma, ou melhor, relações sintagmáticas e relações associativas. As primeiras referem-se à ideia de que os termos da língua estabelecem entre si relações de caráter linear, consecutivas, uma vez que é impossível dois termos ocorrerem ao mesmo tempo na cadeia da fala. As combinações apoiadas na extensão são chamadas de sintagma e, nessa cadeia, "um termo só adquire seu valor porque se opõe ao que o precede ou ao que o segue, ou a ambos" (ibid., p. 142). O sintagma está presente, as relações associativas ou paradigmáticas, 
Linha D'Água (Online), São Paulo, v. 29, n. 1, p. 67-83, jun. 2016

no entanto, estão fora, estão ausentes. Os outros signos que podem estabelecer relações de semelhança ou de dessemelhança se associam na memória e podem produzir relações muito diversas.

Quando começamos esta parte argumentamos que falaríamos sobre princípios e procedimentos saussurianos. Vimos apresentando princípios; o método, depreendemos do que foi dito, é o estrutural. O Saussure, do CLG, resiste a unidades maiores ou baseadas no uso. Sua preocupação parece ser a de preservar o objeto da linguística, a língua. Na explicação sobre o sintagma, exemplos dessa resistência:

Poder-se-ia fazer aqui uma objeção. A frase é o tipo por excelência de sintagma. Mas ela pertence à fala e não à língua (...); não se segue que o sintagma pertence à fala? Não pensamos assim. É próprio da fala a liberdade das combinações; cumpre, pois, perguntar se todos os sintagmas são igualmente livres (1974, p. 144).

A contenção parece dever-se à fidelidade ao objeto, não exatamente à possibilidade de unidades maiores ou da fala, principalmente, serem analisadas. Mas o potencial desse procedimento de análise, acreditamos, se estende e vem sendo comprovado quer aplicado ao som, à palavra, ao sintagma, à frase e, mesmo, ao texto e a outros domínios do conhecimento, como a psicanálise. Neste estudo, mobilizamos as noções de valor, de paradigma e sintagma, aplicados ao poema, a partir das perspectivas de Saussure e de Jakobson de cuja teoria passamos a avaliar aspectos específicos a seguir.

\subsection{Jakobson: o homem-orquestra}

Segundo Ilari (2004, p. 74), Jakobson é um linguista plural que fez "contribuições originais desde a fonologia até a linguagem da poesia, desde a aquisição dita normal, até a patologia linguística". Dosse (1993), por sua vez - de quem tomo emprestado o epíteto de "homem-orquestra" para Jakobson - chama atenção para o interesse do linguista por vários domínios do conhecimento como a teoria matemática da comunicação, a teoria da informação e a antropologia. Em que pese a multiplicidade do perfil do linguista checo, interessa-nos, para este estudo, dois artigos de inquestionável importância quando o domínio em questão é a linguagem, a saber, Dois aspectos de linguagem e dois tipos de afasia e Linguística e poética, ambos, no Brasil, publicados em Linguística e comunicação (1985).

No primeiro deles, o conhecido artigo Dois aspectos da linguagem, dois tipos de afasia, Jakobson (1985) explica o duplo caráter da linguagem. Reporta-se ao Saussure do CLG (1974) que apresenta as relações sintagmáticas e as relações 
Linha D'Água (Online), São Paulo, v. 29, n. 1, p. 67-83, jun. 2016

associativas como esferas distintas do funcionamento da língua. Jakobson retoma essa ideia, reiterando o duplo caráter da linguagem, quais sejam, o da seleção ou paradigmático, e o da combinação ou sintagmático. A princípio, no paradigma estão todas as entidades pertencentes ao código, mas não na mensagem dada. No sintagma estão as entidades linguísticas efetivamente selecionadas para uma dada mensagem. Disso, conclui-se que a fala seleciona entidades linguísticas e as combina em outras mais complexas. Jakobson esclarece, ao afirmar que

Falar implica a seleção de certas entidades linguísticas e sua combinação em unidades linguísticas de mais alto grau de complexidade. Isto se evidencia imediatamente ao nível lexical: quem fala seleciona palavras e as combina em frases, de acordo com o sistema sintático da língua que utiliza; as frases, por sua vez, são combinadas em enunciados (ibid., p. 37).

$\mathrm{Na}$ seleção, temos a escolha de um termo e a possibilidade de substituir por outros que se relacionem com o primeiro seja por equivalência ou por diferença. $\mathrm{Na}$ combinação, observamos que uma unidade linguística serve "ao mesmo tempo, de contexto para unidades mais simples e/ou encontra seu próprio contexto em uma unidade linguística mais complexa" (ibid., p. 39). Ambas as operações têm por base um repertório de signos comum entre emissor e destinatário, caso contrário, a transmissão da mensagem ficaria comprometida. Jakobson avalia, no entanto, que Saussure privilegiou o princípio da linearidade da língua, segundo o qual não podemos pronunciar dois elementos ao mesmo tempo, ou melhor, o linguista genebrino teria pensado mais sobre a concatenação em detrimento da concorrência. Concatenados estariam os signos in praesentia na cadeia da fala; mas eles concorrem com os que estão ausentes. E o funcionamento desses últimos não se limita à formação de séries mnemônicas virtuais relacionadas a cada um dos termos presentes como Saussure propõe. Para Jakobson, então,

Os constituintes de um contexto têm um estatuto de contiguidade, enquanto num grupo de substituição os signos estão ligados entre si por diferentes graus de similaridade, que oscilam entre a equivalência dos sinônimos e o fundo comum (common core) dos antônimos (ibid., p. 40).

Similaridade e contiguidade, é a partir desses dois eixos que o signo linguístico produz interpretantes, ou melhor, o referente do signo é interpretado ora referindo-se ao código, ora ao contexto. Os signos relacionam-se uns com os outros por relações de alternância - na seleção - ou de justaposição - na combinação. 
Linha D'Água (Online), São Paulo, v. 29, n. 1, p. 67-83, jun. 2016

Ainda, "os constituintes de qualquer mensagem estão necessariamente ligados ao código por uma relação interna e à mensagem por uma relação externa. A linguagem em seus diferentes aspectos, utiliza os dois modos de relação" (ibid., p. 41).

O estudo feito sobre a afasia - distúrbio da linguagem que pode incidir ou sobre eixo da seleção ou sobre o da combinação - parece confirmar a compreensão de Jakobson sobre o fenômeno, porque mostra as duas operações in praesentia nas interações verbais. Os afásicos que apresentam distúrbio da similaridade, apoiamse na combinação e no contexto para a produção de mensagens verbais. $\mathrm{O}$ autor explica que "(...) quanto mais uma palavra depender de outras da mesma frase e quanto mais se relacionar com o contexto sintático, menos afetada será pelo distúrbio da fala" (ibid., p. 43). Estão favorecidas as relações de contiguidade, por isso a figura de estilo privilegiada é a metonímia. De acordo com Jakobson, nesse caso,

Tais metonímias podem ser caracterizadas como projeções da linha de um contexto habitual sobre a linha de substituição e seleção; um signo (garfo, por exemplo), que aparece ordinariamente ao mesmo tempo que outro signo (faca, por exemplo) pode ser utilizado no lugar desse signo (ibid., p. 49).

O afásico que teve a capacidade de seleção afetada precisa das relações hierárquicas do sintagma ou da frase, por isso emprega prioritariamente a metonímia. Os que apresentam distúrbio da contiguidade, por sua vez, apoiam-se na relação interna da similaridade. Nesse caso, diminui a extensão e a variedade das frases e perde-se a capacidade de organizar palavras em unidades mais complexas a partir de regras sintáticas específicas. No que se refere às figuras de estilo, "o doente limitado ao grupo de substituição (quando o contexto é falho) usa as similitudes, e suas identificações aproximadas são de natureza metafórica, em oposição às identificações metonímicas familiares aos afásicos do tipo oposto" (ibid., p. 52).

Tendo por base o ensinamento de Jakobson, relacionamos metáfora e paradigma (seleção ou substituição); metonímia e sintagma (combinação ou contexto). Na perspectiva aqui apresentada, o conceito de metáfora não se limita ao da figura de linguagem, segundo o qual ocorre a substituição de um termo real ${ }^{4}$ por um ideal para representar o que se quer nomear, mas, de uma maneira mais abrangente, refere-se à substituição de uma maneira geral, já que qualquer nome pode ser entendido como substituição da coisa que nomeia e, nesse sentido, é metáfora. O de metonímia, por sua vez, refere-se à combinação, à justaposição realizada ora

4 Um exemplo seria substituir o termo real: "mulher ardilosa" pelo termo ideal: "cobra", substituição que tem por base uma relação de semelhança.

TEIXEIRA, I. C. F. Dois aspectos de linguagem e um poema: um estudo estilístico de "Água-Forte" 
Linha D'Água (Online), São Paulo, v. 29, n. 1, p. 67-83, jun. 2016

pelo sintagma ora pelo contexto. Segundo Dubois et al (1997, p. 412), essa figura de estilo designa

(...) o fenômeno linguístico pelo qual uma noção é designada por um termo diferente do que seria necessário, sendo as duas noções ligadas por uma relação de causa e efeito (a colheita pode designar o produto da colheita e não apenas a própria ação de colher), por uma relação de matéria a objeto ou de continente a conteúdo (beber um copo), por uma relação de parte ao todo (uma vela no horizonte).

Esse conceito também se refere a uma transferência de denominação, mas com características singulares que o diferenciam da metáfora, quais sejam, a metonímia mantém com o termo que ela substitui uma relação de contiguidade, ou seja, de proximidade entre duas unidades. Assim é que há uma relação de proximidade ou mesmo de contato entre "beber uma Antártica" ou "beber uma cerveja", entre observar "uma vela no horizonte" ou "um barco no horizonte". Vale ainda uma última aproximação teórica utilizando elementos de semiótica de orientação peirceana, adotados frequentemente por Jakobson, qual seja: a metáfora, a substituição, o paradigma está para o ícone do mesmo modo que a metonímia, a combinação, o sintagma está para o índice.

Metáfora e metonímia, na perspectiva aqui desenvolvida, são figuras de estilo centrais para a compreensão do fenômeno da linguagem e do modo como ela se estrutura. Mas a contribuição de Jakobson não se limita ao estruturalismo. Ilari afirma que:

À sua maneira - uma maneira particularmente brilhante - Jakobson foi funcionalista. Fiel à herança dos praguenses, assimilou a intuição de Bühler de que seria possível distinguir as funções da linguagem, atentando para o maior ou menor relevo dado aos vários fatores de uma mensagem típica (...) (2004, p. 75).

Jakobson retoma as funções da linguagem listadas por Bühler e as complementa. Isso é feito em Linguística e poética, cuja questão central é "Que é que faz de uma mensagem verbal uma obra de arte?" (1985, p. 118-119). O diferencial aqui refere-se à possibilidade de pensar a função poética, que seria predominante em mensagens que reteriam a atenção dos interlocutores por suas próprias características (ILARI, 2004, p. 75). Supõe-se, então, haver um trabalho sobre a camada significante da mensagem considerada poética que faz com que ela tenha características estéticas que as mensagens ordinárias não possuem. Ao elaborar essa teoria, Jakobson fundamenta a teoria da comunicação, estabelece os fatores comunicacionais - emissor, receptor, mensagem, referente, código e canal - e as 
Linha D'Água (Online), São Paulo, v. 29, n. 1, p. 67-83, jun. 2016

funções da linguagem relacionadas a cada um deles - emotiva, conativa, poética, referencial, metalinguística e fática - a partir de um critério de predominância. Auroux (1998, p. 40) sistematiza essas relações do modo que segue:

- função expressiva ou emotiva centrada sobre o destinador (interjeições);

- função conativa, orientada em direção ao destinatário (imperativos);

- função fática, destinada a verificar se o circuito de comunicação funciona ("alô, você me ouve?");

- função metalinguística, centrada sobre o código (“o que você quer dizer?”);

- função poética, centrada sobre a mensagem, que coloca em evidência o lado palpável dos signos, por exemplo na paronomásia, "l’affreux Alfred” [o horrível Alfredo]);

- função referencial, que serve a transmitir uma informação sobre o contexto e que é a função predominante.

Nessa sistematização, o autor apresenta as relações entre os fatores comunicacionais e as funções da linguagem, enfatizando estruturas linguísticas associadas a cada uma delas. É comum associarmos a essa concepção a linguagem enquanto instrumento de comunicação, ou melhor, instrumento ou ferramenta necessária para a transmissão de informações. Mas, nessa perspectiva, é central, conforme vimos, o modo como a mensagem se organiza: como selecionamos no paradigma e organizamos no sintagma. Jakobson, ao estudar as características da função poética explica que nela o princípio de equivalência do eixo da seleção é projetado na combinação. Auroux (1998), reportando-se ao autor de Linguística e poética, explica que a função poética é aquela que põe em evidência o lado palpável dos signos. Vejamos, então, pela análise do poema de Bandeira, os princípios e procedimentos estudados, enfatizando elementos - estruturais e/ou estilísticos - que fazem com que uma mensagem poética seja compreendida como tal.

\section{0 feminino é água-forte}

Nesta parte, o objetivo é aplicar princípios teóricos que vimos apresentando, a saber, a estrutura e o funcionamento dos dois eixos de organização da linguagem e as funções da linguagem, enfatizando o funcionamento da poética. Para isso, analisamos o poema "Água-Forte", de Manuel Bandeira (1986), de Estrela da vida inteira. 
Linha D'Água (Online), São Paulo, v. 29, n. 1, p. 67-83, jun. 2016

\author{
Agua-forte \\ O preto no branco, \\ O pente na pele: \\ Pássaro espalmado \\ No céu quase branco. \\ Em meio do pente, \\ $A$ concha bivalve \\ Num mar de escarlata. \\ Concha, rosa ou tâmara? \\ No escuro recesso, \\ As fontes da vida \\ A sangrar inuiteis \\ Por duas feridas. \\ Tudo bem oculto \\ Sob as aparências \\ Da água-forte simples: \\ De face, de flanco, \\ O preto no branco.
}

O poema inicialmente surpreende pelo aparente hermetismo. Precisamos desacomodar sentidos estabilizados e baseados no senso comum. Um primeiro obstáculo a transpor, portanto, é a compreensão do repertório verbal mobilizado que propõe novas redes de significações. Começamos então por um levantamento dos signos utilizados, cujo objetivo é levantar sentidos desconhecidos ou difusos e, eventualmente, direcioná-los para certas possibilidades de interpretação. Começamos por água-forte que se refere a uma "técnica de gravura a entalhe em que se marcam traços na camada protetora (de cera, p.ex.) de uma placa de metal, a qual, imersa em ácido nítrico, tem esses traços transformados em sulcos pela ação corrosiva do ácido" (HOUAISS; VILLAR, 2001, p. 124). Estamos, portanto, diante de uma gravura, de uma imagem a ser produzida pelo signo verbal. A próxima expressão sobre a qual nossa atenção se volta é o preto no branco que abre e fecha o poema, primeiro e último verso. Se temos uma água-forte, no sentido de gravura, esse verso pode ser compreendido como uma moldura da imagem. E preto no branco, dentre outros sentidos possíveis, significa escrever, para não ficar só em palavras; 
Linha D'Água (Online), São Paulo, v. 29, n. 1, p. 67-83, jun. 2016

lavrar um documento 5 . A ideia parece ser a de registrar, para que a representação não se perca.

A seguir, temos outros signos cujos sentidos se estabelecem em função das relações que estabelecem com os outros do sistema. Homônimos, signos constituídos por significantes idênticos e significados distintos, como pente, (ibid., p. 2180) que pode ser utensílio com o qual se penteiam ou se desembaraçam os cabelos; artefato onde se encaixam as balas em armas automáticas; púbis (ibid., p. 2330) que é a parte triangular no baixo abdome, que nos adultos é recoberto por pelos; designação dos pelos da genitália externa, entre outros. Há também escarlata, ou escarlate, vermelho muito vivo; espalmado, aberto com a palma da mão; concha, (ibid., p. 785) envoltório do corpo dos moluscos ${ }^{6}$ formado por duas peças; bivalve, (ibid., p. 464) que apresenta duas valvas ${ }^{7}$ - cada uma das peças da concha dos moluscos (ibid., p. 2826) -, que podem ser calcárias, de vida aquática.

Inicialmente, esclarecemos que observar a seleção dos signos é necessário para que, a partir das escolhas operadas por Bandeira, alguns paradigmas presentes no poema que indicam aspectos de sua significação, possam se configurar como tal. Comecemos por esse repertório verbal então. Um paradigma relacionado ao que é úmido, líquido ou mesmo corrosivo pode ser identificado já que há termos como água-forte, mar, concha, fontes. A umidade provém também dos líquidos que circulam no corpo - ou, de modo mais geral, na natureza - e que garantem a manutenção da vida: sangrar por duas feridas. É possível pensarmos também em um paradigma ligado ao que é invertebrado - por isso, mais flexível ou macio - pássaro espalmado, concha bivalve, concha, rosa, tâmara. Vale destacar também o número 2, materializado por preto e branco; pente e pele; pássaro espalmado, gesto que produz a imagem de um pássaro com as duas asas espalmadas, abertas; além dessas duplas, há concha bivalve, duas feridas.

Aos poucos participamos da produção da gravura. Passamos a repetir o gesto em nossa mente. Água-forte indica a composição feita com o ácido nítrico, composição úmida e corrosiva, em função do ácido. As cores predominantemente usadas para a composição são preto, branco e escarlata. Escarlata é vermelho, vermelho sangra inútil por duas feridas; dois são os ovários, fontes da vida, que sangram no escuro recesso ou em meio do pente ou do púbis. Tudo bem oculto, na

5 Adaptado de http://michaelis.uol.com.br/moderno/portugues/index.php?lingua=portugues-portugues \&palavra=preto. Acesso em: 29 set. 2015.

6 Molusco: animais invertebrados, marinhos, de água doce ou terrestre, que compreende os caramujos, ostras e lulas, entre outros (HOUAISS; VILLAR, 2001: 1948).

7 Valva: cada uma das peças das conchas dos moluscos bivalves. 
Linha D'Água (Online), São Paulo, v. 29, n. 1, p. 67-83, jun. 2016

aparência da água-forte simples: há o preto no branco, os pelos no pente, pelos da genitália, na pele, possivelmente branca.

É possível supor um movimento do olhar que vai do que está aparente, à vista, lado de fora, ou ainda de face e de flanco, em direção ao que está no escuro recesso, do lado de dentro. O leitor move-se do lado de fora para o lado de dentro, movimenta-se para ver bem e compor a água-forte, retrato da genitália feminina. Fundamental, a esta altura da interpretação, é chamar atenção para o trabalho feito no eixo da seleção, responsável pela substituição que colabora com a plasticidade do poema e que faz de um tema improvável motivo para o poema.

Em Linguística e Poética, Jakobson (1985) explica que para dar conta do critério que define a função poética é necessário recorrer à seleção e à combinação, mas, para caracterizar adequadamente essa função é necessário compreender que "a função poética projeta o princípio de equivalência do eixo de seleção sobre o eixo de combinação" (ibid., p. 130). Tomando essa proposição como verdadeira, entendemos que a poesia tende a reiterar conteúdos pelo trabalho sobre a camada significante, entendemos também que há uma tendência na poesia lírica em construir sequências, que se situam na combinação, equivalentes. "Água-Forte" parece representar bem esse princípio, pois as imagens produzidas pelas sequências - cada um dos versos - remetem todas ao tema da gravura-poema: a genitália feminina. Assim é que preto no branco, pente na pele, pássaro espalmado e, sucessivamente, cada um dos versos do poema são equivalentes, mesmo se mostram pontos de vista diferentes do objeto representado.

\section{Conclusão}

Entendemos que o procedimento de análise do poema permite observar princípios propostos pelos autores estudados. Assim, em consonância com o CLG (1974), podemos dizer que o signo tem um lado palpável e um conteúdo. Esse conteúdo não se constitui somente com o signo em presença, mas também em função dos signos que não estão presentes, mas que colaboram com o(s) sentido(s) atualizado(s) em um texto/mensagem específico. Mais, os signos relacionam-se uns com os outros por relações de alternância ou de justaposição. Essas relações, que evidenciam o funcionamento do paradigma e do sintagma, são simultaneamente usadas pela linguagem. A partir da leitura que fazemos de Jakobson (1985), entendemos que tanto o afásico do eixo da combinação - que recorre ao paradigma para se comunicar -, quanto a função poética - que aponta para a recorrência da seleção no eixo sintagmático - mostram o paradigma em presença, atuando e atualizando sentidos em textos/mensagens específicos. Entendemos, portanto, que 
Linha D'Água (Online), São Paulo, v. 29, n. 1, p. 67-83, jun. 2016

Jakobson parte de ideias saussurianas, mas as desenvolve, apresentando formas alternativas - e complementares - de compreender a linguagem.

Pode-se argumentar que a questão do sujeito não é tratada de modo significativo neste estudo e que isto aponta para uma das limitações dos procedimentos aplicados. Os limites do estruturalismo, a propósito, têm sido tema recorrente nos estudos linguísticos. Guimarães argumenta nessa direção e entende que, ao estabelecer a língua como objeto da linguística, Saussure "constitui um objeto no qual não estavam incluídas as questões do sujeito, da relação com o mundo, e mesmo a questão da significação, que foi substituída por aquilo a que ele chamou de valor das formas linguísticas" (1997, p. 117). Elementos teóricos elaborados pelo estruturalismo, quais sejam, conceito de significante e de significado, de arbitrariedade e de valor, por exemplo, apontam para o objeto de estudo ou para suas qualidades intrínsecas. Não importam as possíveis relações da língua com a exterioridade. Trata-se de estudar a língua, sistema gramatical que existe virtualmente em cada cérebro, em si mesma, sem se preocupar com a relação entre as formas da língua e os objetos do mundo ou do pensamento.

Sobre o funcionalismo, por sua vez, costuma-se dizer que concebe a língua como um instrumento, necessário para a transmissão de informação. O problema aqui é que a ideia de instrumento apresenta a língua como uma espécie de ferramenta, que os falantes utilizam com determinados propósitos, e que está sujeita apenas a adaptações determinadas individualmente. Possenti (2004, p. 361) critica essa concepção e avalia que "aceitar que seja um instrumento significaria tomar a língua como algo exterior ao sujeito. Ora, o sujeito (...) é o que é, em grande medida, por ser efeito de linguagem (...)". Ainda, entende-se, sob esse ponto de vista, que se todos os fatores comunicacionais estiverem envolvidos apropriadamente e se não houver nenhum ruído capaz de interromper a transmissão da informação, ela chegará de forma inequívoca a seu ponto de destino. O processo de comunicação seria um sistema composto por elementos que se relacionam no interior de um sistema fechado, de que a língua é apenas um componente. Pode-se pensar então que o funcionalismo não leva em conta a opacidade da língua. Entretanto, entendemos que Jakobson não deve ser considerado um estruturalista no sentido mais estrito do termo, porque considera os interlocutores no processo comunicativo.

Podemos dizer que nas vertentes estruturalistas predomina a ideia de língua como sistema autônomo, cuja significação independe de fatores externos ao próprio sistema. E entendemos que o estruturalismo tem se defrontado com seus limites, mas também que tem oferecido procedimentos que podem servir de base para os estudos linguísticos, tal como os que aqui usamos e que indicam e mostram, nesse caso, qualidades estéticas que colaboram na configuração do que consideramos 
Linha D'Água (Online), São Paulo, v. 29, n. 1, p. 67-83, jun. 2016

artístico. Além disso, os princípios tornam-se procedimentos de análise pela ação, pelo gesto de leitura, o que aponta para os locutores/interlocutores - estudantes envolvidos - e para o funcionamento discursivo da linguagem que pode produzir diferentes sentidos em função de diferentes leitores.

\section{Referências}

AUROUX, Sylvain. A filosofia da linguagem. Tradução de José Horta Nunes. Campinas (SP): Editora da UNICAMP, 1998.

BANDEIRA, Manuel. Estrela da vida inteira. Rio de Janeiro: José Olympio, 1986.

CÂMARA JÚNIOR, Joaquim Mattoso. Mattoso Câmara e a estilística. In: Uchôa, Carlos Eduardo Falcão (Org.). Dispersos de J. Mattoso Câmara Jr. Rio de Janeiro: Lucerna, 2004.

CARA, Salete de Almeida. A poesia lírica. São Paulo: Ática, 1986.

COELHO, Nelly Novaes. Literatura e Linguagem. São Paulo: Quíron, 1980.

DOSSE, François. O corte saussureano. In: . História do estruturalismo: o campo do signo, 1945/1966. Tradução de Álvaro Cabral. São Paulo: Ensaio; Campinas, SP: UNICAMP, 1993.

. O homem-orquestra: Roman Jakobson. In: . História do estruturalismo: o campo do signo, 1945/1966. Tradução de Álvaro Cabral. São Paulo: Ensaio; Campinas, SP: UNICAMP,1993.

DUBOIS, Jean et al. Dicionário de linguística. São Paulo: Cultrix, 1997.

GUIMARÃES, Eduardo. Os limites do sentido: um estudo histórico e enunciativo da linguagem. Campinas, SP: Pontes, 1995.

HOUAISS, Antônio; VILLAR, Mauro de Salles. Dicionário Houaiss de lingua portuguesa. Rio de Janeiro: Objetiva, 2001.

ILARI, Rodolfo. O estruturalismo linguístico: alguns caminhos. In: MUSSALIN, Fernanda; BENTES, Anna Christina. Introdução à linguística: fundamentos epistemológicos. São Paulo: Cortez, 2004. 3 v.

JAKOBSON, Roman. Linguística e comunicação. Tradução de Izidoro Blikstein e José Paulo Paes. São Paulo: Cultrix, 1985.

TEIXEIRA, I. C. F. Dois aspectos de linguagem e um poema: um estudo estilistico de "Água-Forte" 
Linha D'Água (Online), São Paulo, v. 29, n. 1, p. 67-83, jun. 2016

Linguistics and Poetics. Disponível em: <http://www.akira.ruc.dk/ new/Ret_og_Rigtigt/Jakobson_Eks_15_F12.pdf >.Acesso em: 06 fev. 2016.

Linguística e teoria da comunicação. In: . Linguistica e comunicação. Izidoro Blikstein e José Paulo Paes. São Paulo: Cultrix, 1985.

POSSENTI, Sírio. Teoria do discurso: um caso de múltiplas rupturas. In: MUSSALIN, Fernanda; BENTES, Anna Christina. Introdução à linguistica: fundamentos epistemológicos. São Paulo: Cortez, 2004.3v.

SAUSSURE, Ferdinand de. Curso de linguística geral. Tradução de Antônio Chelini, José Paulo Paes e Izidoro Blikstein. 6.ed.São Paulo: Cultrix, 1974.

Recebido: 29/02/2016

Aprovado: 15/06/2016 